\title{
Assessing duplication and loss of APETALA1/FRUITFULL homologs in Ranunculales
}

\author{
Natalia Pabón-Mora ${ }^{1,2 *}$, Oriane Hidalgo ${ }^{3}$, Stefan Gleissberg ${ }^{4}$ and Amy Litt ${ }^{2}$ \\ ${ }^{1}$ Grupo de Biotecnología, Instituto de Biología, Universidad de Antioquia, Medellín, Colombia \\ 2 The New York Botanical Garden, Bronx, NY, USA \\ ${ }^{3}$ Laboratori de Botànica, Facultat de Farmàcia, Universitat de Barcelona, Barcelona, Spain \\ ${ }^{4} 38$ Fairview Avenue, Athens, OH, USA
}

\section{Edited by:}

Jill C. Preston, University of

Vermont, USA

Reviewed by:

David Smyth, Monash University, Australia

Koen Geuten, KULeuven, Belgium

${ }^{*}$ Correspondence:

Natalia Pabón-Mora, Instituto de

Biología, Universidad de Antioquia,

Calle 70 No 52-21, AA 1226,

Medellin, Colombia

e-mail:npabonmora@biologia. udea.edu.co
Gene duplication and loss provide raw material for evolutionary change within organismal lineages as functional diversification of gene copies provide a mechanism for phenotypic variation. Here we focus on the APETALA1/FRUITFULL MADS-box gene lineage evolution. $A P 1 / F U L$ genes are angiosperm-specific and have undergone several duplications. By far the most significant one is the core-eudicot duplication resulting in the euAP1 and euFUL clades. Functional characterization of several eUAP1 and euFUL genes has shown that both function in proper floral meristem identity, and axillary meristem repression. Independently, euAP1 genes function in floral meristem and sepal identity, whereas euFUL genes control phase transition, cauline leaf growth, compound leaf morphogenesis and fruit development. Significant functional variation has been detected in the function of pre-duplication basal-eudicot FUL-like genes, but the underlying mechanisms for change have not been identified. FUL-like genes in the Papaveraceae encode all functions reported for euAP1 and euFUL genes, whereas FUL-like genes in Aquilegia (Ranunculaceae) function in inflorescence development and leaf complexity, but not in flower or fruit development. Here we isolated FUL-like genes across the Ranunculales and used phylogenetic approaches to analyze their evolutionary history. We identified an early duplication resulting in the RanFL1 and RanFL2 clades. RanFL1 genes were present in all the families sampled and are mostly under strong negative selection in the MADS, I and K domains. RanFL2 genes were only identified from Eupteleaceae, Papaveraceae s.l., Menispermaceae and Ranunculaceae and show relaxed purifying selection at the $\mathrm{I}$ and $\mathrm{K}$ domains. We discuss how asymmetric sequence diversification, new motifs, differences in codon substitutions and likely protein-protein interactions resulting from this Ranunculiid-specific duplication can help explain the functional differences among basal-eudicot FUL-like genes.

\section{Keywords: gene duplication, APETALA1, FRUITFULL, basal-eudicots, FRUITFULL-like, Ranunculales}

\section{INTRODUCTION}

The APETALA1/FRUITFULL genes are best known for the roles of APETALA1 (AP1), CAULIFLOWER (CAL) and FRUITFULL (FUL) paralogs in Arabidopsis thaliana. Altogether AP1, CAL and $F U L$ are responsible for proper floral meristem identity (Ferrándiz et al., 2000); in addition, AP1 plays a key role promoting perianth identity. Because of this, it was included as an A-function gene in the ABC model of flower development (Irish and Sussex, 1990; Coen and Meyerowitz, 1991; Bowman et al., 1993; Gustafson-Brown et al., 1994; Ferrándiz et al., 2000). CAL is mostly redundant with $A P 1$, however, it has been shown to play an independent role in petal formation (Kempin et al., 1995; Castillejo et al., 2005). FUL plays unique roles in proper cauline leaf development and fruit development, and is also a key factor in meristem maintenance and branching (Mandel and Yanofsky, 1995; Gu et al., 1998; Melzer et al., 2008). A fourth, less studied paralog, AGL79, is highly divergent in sequence and only expressed in roots, and it has not been functionally characterized
(Parenicová et al., 2003). These paralogous genes are the result of duplications in the AP1/FUL gene lineage: whereas the origin of $A P 1$ and $F U L$ is the result of a duplication that resulted in the $e u A P 1$ and $e u F U L$ gene clades coincident with the origin of the core-eudicots, the close paralogs AP1 and CAL are likely the result of genome duplication events correlated with the diversification of the Brassicaceae (Blanc et al., 2003; Bowers et al., 2003; Alvarez-Buylla et al., 2006; Barker et al., 2009; Figure 1A).

The core-eudicot duplication was followed by sequence changes in euAP1 proteins that produced a transcription activation (Cho et al., 1999) and a protein modification motif (Yalovsky et al., 2000). euFUL proteins instead retained the six hydrophobic amino-acid motif that is characteristic of pre-duplication proteins (FUL-like proteins). The function of this motif is unknown (Litt and Irish, 2003; Figure 1A). Together euAP1 and euFUL genes promote floral meristem identity (Huijser et al., 1992; Berbel et al., 2001; Vrebalov et al., 2002; Benlloch et al., 2006). Additionally, euAP1 genes play a unique role in the specification 


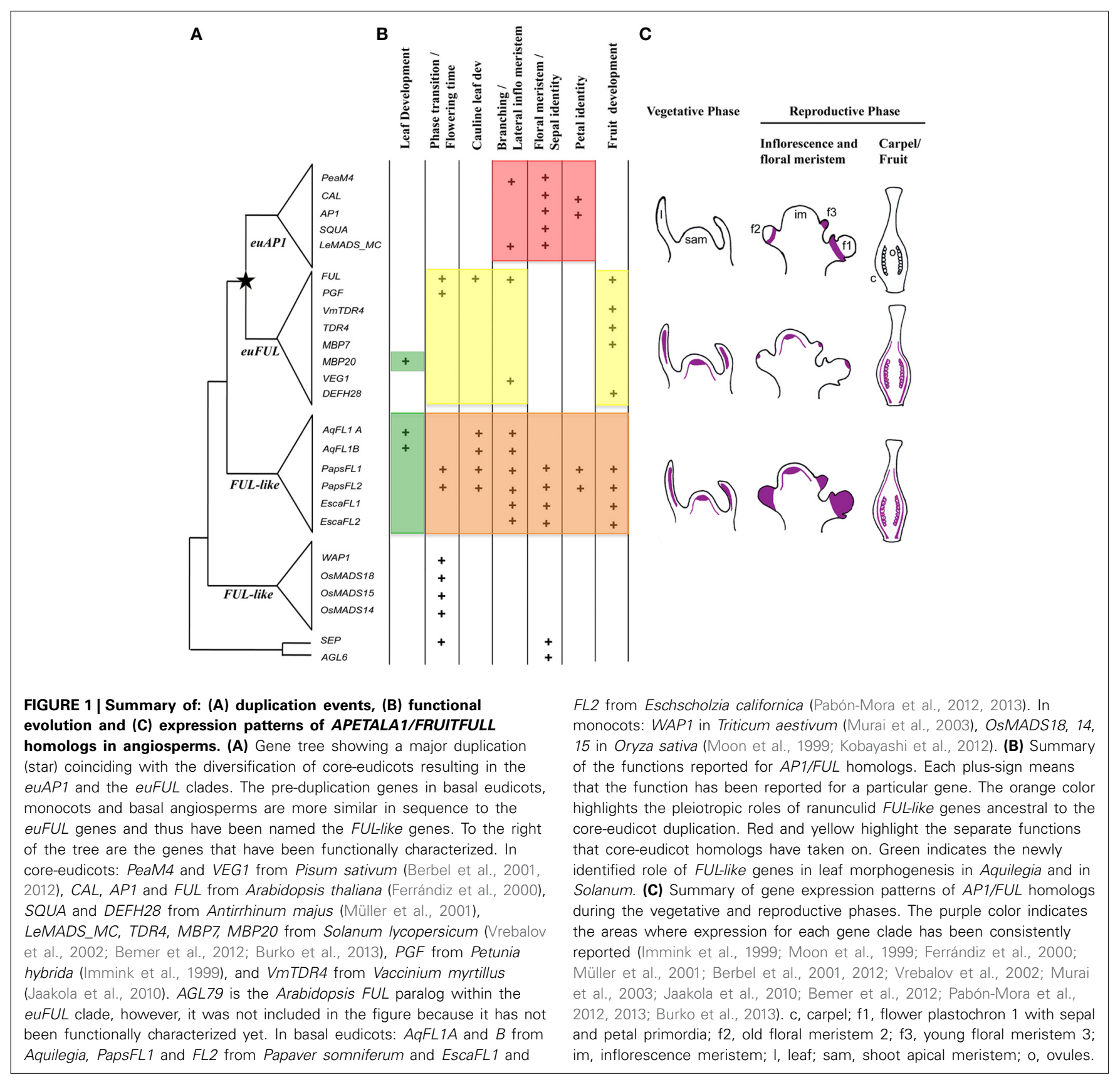

of sepal (and in Arabidopsis, petal) identity (Berbel et al., 2001; Vrebalov et al., 2002; Benlloch et al., 2006) whereas, euFUL genes function in the reproductive phase transition, proper cauline leaf development, branching, and fruit development as well as compound leaf development (Immink et al., 1999; Müller et al., 2001; Jaakola et al., 2010; Bemer et al., 2012; Berbel et al., 2012; Torti et al., 2012; Burko et al., 2013; Meyer et al., unpublished data; Figure 1B). The functional differences between $e u A P 1$ and $e u F U L$ genes suggest an evolutionary scenario of either sub- or neofunctionalization after duplication, and studies of the function of FUL-like genes in basal eudicot Ranunculales (ranunculids) evaluated these two hypotheses. The FUL-like genes of Papaver somniferum (opium poppy; Papaveraceae) were shown to play pleiotropic roles that include essentially all those reported for euAP1 and euFUL genes; thus, sub-functionalization was postulated as the outcome of the core-eudicot AP1/FUL duplication (Figure 1B; Pabón-Mora et al., 2012). However, functional analyses in E. californica (California poppy), also in Papaveraceae, showed that FUL-like genes in this species are involved only in a subset of these functions (Figure 1B: Pabón-Mora et al., 2012), and studies of FUL-like gene function in Aquilegia coerulea (columbine; Ranunculaceae) have shown only a role in regulating inflorescence branching and a role in compound leaf morphogenesis (Pabón-Mora et al., 2013; Figure 1B).

These studies on the FUL-like genes of ranunculids detected significant variation in the function of basal eudicot FUL-like 
genes. This observed functional diversity is not associated with changes in expression; in general all the ranunculid FUL-like genes are turned on in the shoot apical meristem and leaves, and expression is maintained throughout inflorescence and flower development, in all floral organs and fruit (Figure 1C). Thus, functional differences may instead be the result of protein sequence changes leading to differences in interactions with other transcription factors or downstream factors. Such sequence changes may hold clues to observed differences in function among genes belonging to different taxa (e.g., Papaveraceae vs. Ranunculaceae) as well as to the selective forces operating on genes of different paralagous lineages. Changes in developmental functions among paralogous genes are often accompanied by changes in rates and patterns of sequence evolution among loci (Purugganan and Suddith, 1998; Lawton-Rauh et al., 1999) and faster rates of evolution are usually associated with the occurrence of genetic redundancy (Lawton-Rauh et al., 1999). To understand functional evolution within ranunculid FULlike genes this study had two main goals: (1) to explore in detail FUL-like gene duplications and losses in Ranunculales to establish the relationship among functionally characterized copies, and (2) to investigate differences in protein motifs and rates of evolution and selection across FUL-like genes in members of the ranunculids. The results of these analyses were used to understand the variation in FUL-like gene function among poppy, California poppy, and columbine and to identify changes in protein evolution that may be linked with differences in protein interaction capabilities across ranunculid FUL-like proteins.

\section{MATERIALS AND METHODS PLANT MATERIAL}

Leaf and floral tissue was obtained from a number of basal eudicots, mostly within Papaveraceae s.l., Berberidaceae and Ranunculaceae, as well as non-eudicots within Aristolochiaceae (Piperales). Fresh material was obtained from living collections at The New York Botanical Garden, Bronx, NY or at the Systematics Garden at Lehman College, Bronx, NY. Voucher information for all species is listed in Table S1.

\section{CLONING AND CHARACTERIZATION OF FUL-like GENES}

Total RNA was extracted from $0.5-1 \mathrm{~g}$ of young leaf or floral buds using TRIZOL reagent (Invitrogen) and was DNaseI-treated (Roche) to remove residual genomic DNA. $2 \mu \mathrm{g}$ were used as template for cDNA synthesis with SuperScript III reverse transcriptase (Invitrogen) according to the manufacturer's instructions using the OligodT primer supplied. The resulting cDNA was diluted 1:10 for use in amplification reactions. Initial amplifications using degenerate primers to recover a pool of MADS-box genes were done as in Litt and Irish (2003), with two modifications; (1) the amplification program began with a $5 \mathrm{~min}$ activation step at $95^{\circ} \mathrm{C}$, and five initial cycles with an incubation step of $30 \mathrm{~s}$ at $95^{\circ} \mathrm{C}$, a $30 \mathrm{~s}$ annealing step at $42^{\circ} \mathrm{C}$ and a 1 min extension at $72^{\circ} \mathrm{C}$, followed by 30 cycles with an incubation step at $95^{\circ} \mathrm{C}$ for $30 \mathrm{~s}$, a $30 \mathrm{~s}$ annealing step at $50^{\circ} \mathrm{C}$ and a $1 \mathrm{~min}$ extension at $72^{\circ} \mathrm{C}$. The products of this amplification were diluted $1: 20$ and used as template in successive reactions. In addition to the primers used by Litt and Irish (2003) the forward degenerate primer ATGGRDAGAGGWAGGGTWCAG, designed to bind the beginning of the MADS domain, was used in combination with all degenerate reverse primers designed to amplify the full coding sequence towards the $5^{\prime}$ end of the FUL-like genes. All PCR products were run on a $1 \%$ agarose gel and amplicons between 600 and $900 \mathrm{bp}$ in size were cloned into $\mathrm{pCR}^{\circledR} 2.1-\mathrm{TOPO}^{\circledR}$ (Invitrogen). Clones were grown overnight, plasmid was extracted with the Qiagen miniprep Kit (Invitrogen) and sequenced at the DNA Yale Sequencing Center (CT).

In addition to degenerate PCR, we searched public databases, using BLAST (Altschul et al., 1990) and obtained 16 FUL-like genes from the transcriptomes available at the phytometasyn project website (http://www.phytometasyn.ca) and 29 FUL-like genes from GenBank (http://www.ncbi.nlm.nih.gov/genbank/). Sequences from 51 species and all families in Ranunculales (Eupteleaceae, Papaveraceae, Lardizabalaceae, Menispermaceae, Berberidaceae and Ranunculaceae) were included except Circaeasteraceae, from which material could not be obtained. Outgroups included representatives of the Magnoliaceae, Lauraceae, Saururaceae and Poaceae (Table S1).

\section{PHYLOGENETIC ANALYSES}

Between 40 and 60 clones were sequenced per species. If variation was found among clones, the criteria to distinguish allelic variation at a single locus from different loci were the same used by Litt and Irish (2003). FUL-like sequences in the transcriptome databases were assembled into contigs and screened for polymorphisms using Sequencher DNA sequencing software (GeneCodes, Ann Arbor, MI): if different hits had less than $5 \%$ variation a consensus sequence was generated; if the difference among hits was larger, the two sequences were both kept in the analysis. Only sequences containing at least part of the MADS domain and the FUL-motif were included in the analysis. Sequences were compiled using Bioedit (http://www.mbio.ncsu. edu/bioedit/bioedit.html), and then aligned using the online version of MAFFT (http://mafft.cbrc.jp/alignment/server/) (Katoh et al., 2002), with a gap open penalty of 3.0, an offset value of 0.3 , and all other default settings. The alignment was then refined by hand using Bioedit. The nucleotide alignment for 109 full-length sequences from 51 species was used for phylogenetic analyses. The amino acid alignment, also generated in Bioedit, was used to identify conserved motifs as well as single amino acids that were diagnostic of clades; these were optimized and visualized in MacClade4.08a ${ }^{\circledR}$ (Maddison and Maddison, 2005). The Magnoliid sequences (Ma.gr.AP1 and Pe.am.AP1) were used to root the trees, and all non-Ranunculid sequences were used as outgroup.

Maximum Likelihood (ML) phylogenetic analyses were performed in RaxML-HPC2 BlackBox (Stamatakis et al., 2008) on the CIPRES Science Gateway (Miller et al., 2009). The best performing evolutionary model was obtained by the Akaike information criterion (AIC; Akaike, 1974) using the program jModelTest v.0.1.1 (Posada and Crandall, 1998). Bootstrapping was performed according to the default criteria in RAxML where bootstrapping stopped after 200 replicates when the criteria were met. 


\section{RELATIVE RATES OF EVOLUTION}

To test for evidences of changes in selection constraints in the Ranunculid FUL-like gene tree, we performed a series of likelihood ratio tests (LRTs) using the branch-specific model implemented by the CodeML program of PAML package v.4.6 (Yang, 2007). We compared the one ratio model that assumes a constant $\mathrm{dN} / \mathrm{dS}$ ratio $(=\omega$, per site ratio of nonsynonymous $-\mathrm{dN}$ to synonymous - dS- substitution) along tree branches, against a two-ratio model that assumes a different ratio for a designated ranunculid FUL-like subclade (foreground) relative to the remaining sequences (background). For each of the LRTs, twice the difference of $\log$ likelihood between the models $(2 \Delta \operatorname{lnL})$ was compared to critical values from a $\chi 2$ distribution, with degree of freedom equal to the differences in number of estimated parameters between models. The test was conducted for the entire dataset and also for each of the functional domains defined for MADS-box genes. These analyses on the M, IK, and C domains were performed in order to evaluate whether there was a difference in their rates of evolution in different taxa, given their key roles in DNA binding (M), protein dimerization (IK), and multimerization $(\mathrm{C})$.

\section{RESULTS}

\section{FUL-like GENE CLONING IN RANUNCULALES}

In order to gain a better understanding of the basis of the functional diversity reported for FUL-like genes in the basal eudicot order Ranunculales, we looked at patterns of evolution among these genes. We isolated FUL-like copies from species representing the phylogenetic breadth of the Ranunculales, an order with nearly 202 genera and 4500 species (APG, 2009; Wang et al., 2009; Figures 2, 3), and reconstructed the evolutionary history of the gene lineage in this clade. Ranunculales includes the early-diverging families Eupteleaceae and Papaveraceae s.l., as well as the core Ranunculales Lardizabalaceae, Circaeasteraceae, Menispermaceae, Berberidaceae and Ranunculaceae. We generated a dataset consisting of 109 FUL-like gene sequences (Table S1) from Eupteleaceae, Papaveraceae s.l., Lardizabalaceae, Menispermaceae, Berberidaceae and Ranunculaceae, as well as the outgroup basal angiosperm and monocot families Magnoliaceae, Lauraceae, Saururaceae, Aristolochiaceae and the monocot family Poaceae. Sequences from Circeasteraceae were not included due to lack of availability of material.

Clones that were recovered with degenerate primers either span the entire coding sequence or are missing 10-20 amino acids (AA) from the start of the 60 AA MADS domain. The alignment includes $60 \mathrm{AA}$ in the MADS domain, 35-40 in the I domain, 70-75 in the $\mathrm{K}$ domain, and 90 in the C-terminal domain. Among Ranunculales, paralogous gene sequence similarity ranges from 52 to $95 \%$, and the variation in sequence similarity between outgroup and ingroup ranges from 50 to $75 \%$. In the C-terminal portion, all protein sequences show the previously described FUL-like motif (Litt and Irish, 2003; Preston and Kellogg, 2006; Shan et al., 2007). Alignment of the predicted amino acid sequences of the entire dataset reveals a high degree of conservation in the $\mathrm{M}, \mathrm{I}$, and $\mathrm{K}$ regions until position 184. In most plant MADS proteins, the structurally conserved Keratin-like domain $(\mathrm{K})$, forms three amphipathic helices (K1,
$\mathrm{K} 2$, K3) that are important for strength and specificity of protein dimerization (Yang et al., 2003). Usually the three putative amphipathic $\alpha$-helices of the $\mathrm{K}$ domain have heptad repeats (abcdefg $)_{n}$, in which a and $\mathbf{d}$ positions are occupied by hydrophobic amino-acids. The putative amphipathic $\alpha$-helices of ranunculid FUL-like proteins, K1 (AA 97-110), K2 (AA 121-143) and K3 (AA 152-258), conform to this expected pattern. (Figure S1). Within K1, positions $99(\mathrm{E}), 102(\mathrm{~K}), 104(\mathrm{~K}), 106(\mathrm{~K}), 108$ $(\mathrm{E})$, and $111(\mathrm{Q})$, and within $\mathrm{K} 2$ positions $119(\mathrm{G}), 128(\mathrm{~K})$, $129(\mathrm{E}), 134(\mathrm{E}), 136(\mathrm{Q})$, are conserved in all Ranunculales and outgroup FUL-like predicted protein sequences, with a few exceptions (Figure S1). The C-terminal domain, beginning after the hydrophobic amino acid located in position 184 , is more variable, but three regions of high similarity can be identified: (1) a region rich in tandem repeats of polar uncharged amino acids (QNQ), particularly glutamine (Q), between positions 190-230 in the alignment; (2) a highly conserved, predominantly hydrophobic motif unique to ranunculids at positions 226-256, with the sequence QNS-P/LS/TFLLSQSE/LPSLN/TI, and (3) a negatively charged region rich in glutamic acid (E) before the conserved FUL-motif LMPPWML (Figure 2).

\section{GENE DUPLICATION AND LOSS OF FUL-like GENES IN RANUNCULALES}

A total of 910 characters were included in the matrix, of which 645 (71\%) were informative. Maximum likelihood analysis recovered a single duplication event early in the diversification of the Ranunculales resulting in two clades of FUL-like genes, here named RanFL1 and RanFL2 (Figure 3). Bootstrap support for the RanFL1 and RanFL2 clades is low $(<50)$, however, within each clade, gene copies from the same family are grouped together with strong support, and the relationships among gene clades are mostly consistent with the phylogenetic relationships of the sampled taxa (Wang et al., 2009). An exception is the position of the Menispermaceae sequences as sister to the Papaveraceae s.l. sequences-although with long branches and low support-in both gene clades; phylogenetic analyses have shown Menispermaceae as the sister group to [Ranunculaceae + Berberidaceae] (Wang et al., 2009). Other inconsistent positioning is the placement of Lardizabalaceae as sister to [Papaveraceae + Menispermaceae], while it was sister to [Menispermaceae (Ranunculaceae + Berberidaceae)] in Wang et al. (2009).

Additional duplications and putative losses can also be detected. The RanFL1 clade contains two paralogous Lardizabalaceae clades, LarFL1a and LarFL1b, but the RanFL2 clade lacks sequences from this family. This suggests that LarFL1 genes underwent an independent duplication, and that LarFL2 members have been lost or are yet to be found. RanFL2 sequences were also not recovered from Berberidaceae. Additional taxonspecific duplications were found in Pseudofumaria lutea, E. californica (Papaveraceae sl.), Berberis gilgiana and Nandina domestica (Berberidaceae), A. coerulea, Eranthis hyemalis and Ranunculus sceleratus (Ranunculaceae) within the RanFL1 clade. Similarly, duplications were found in Bocconia frutescens (Papaveraceae) within the RanFL2 clade. Finally, duplications in both clades (RanFL1 and RanFL2) were evident in Argemone 


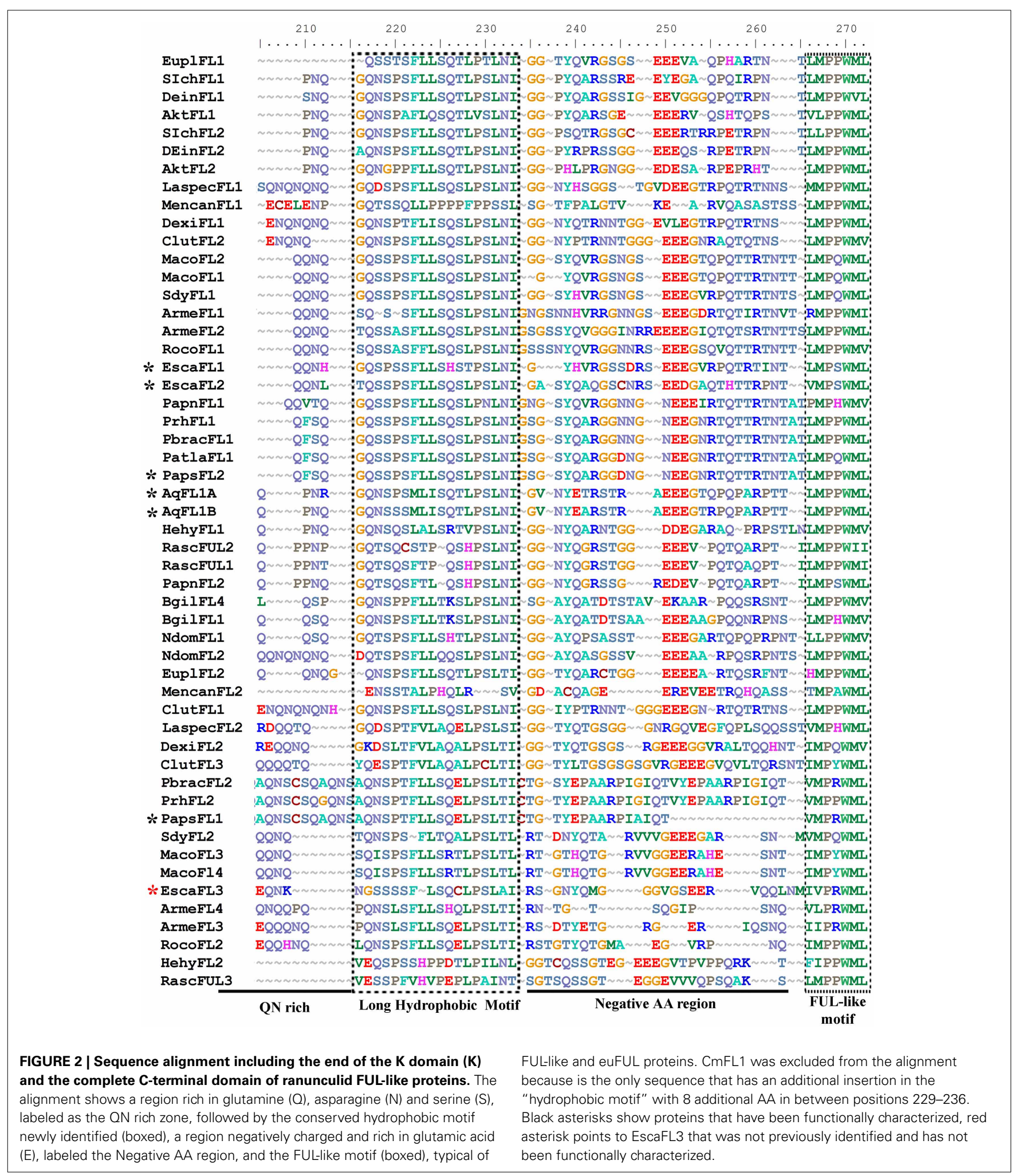

mexicana, Macleaya cordata (Papaveraceae), and Ranunculus bulbosus (Ranunculaceae). Since most of these species are thought to be polyploid (Index to Plant Chromosome Numbers; Missouri Botanical Garden, http://www.tropicos.org/Project/
IPCN), additional duplicates are likely derived from whole genome duplications. If so, these transcription factors, that are thought to function as tetramers with other MADS box proteins at least in flower development (Smaczniak et al., 2012), 


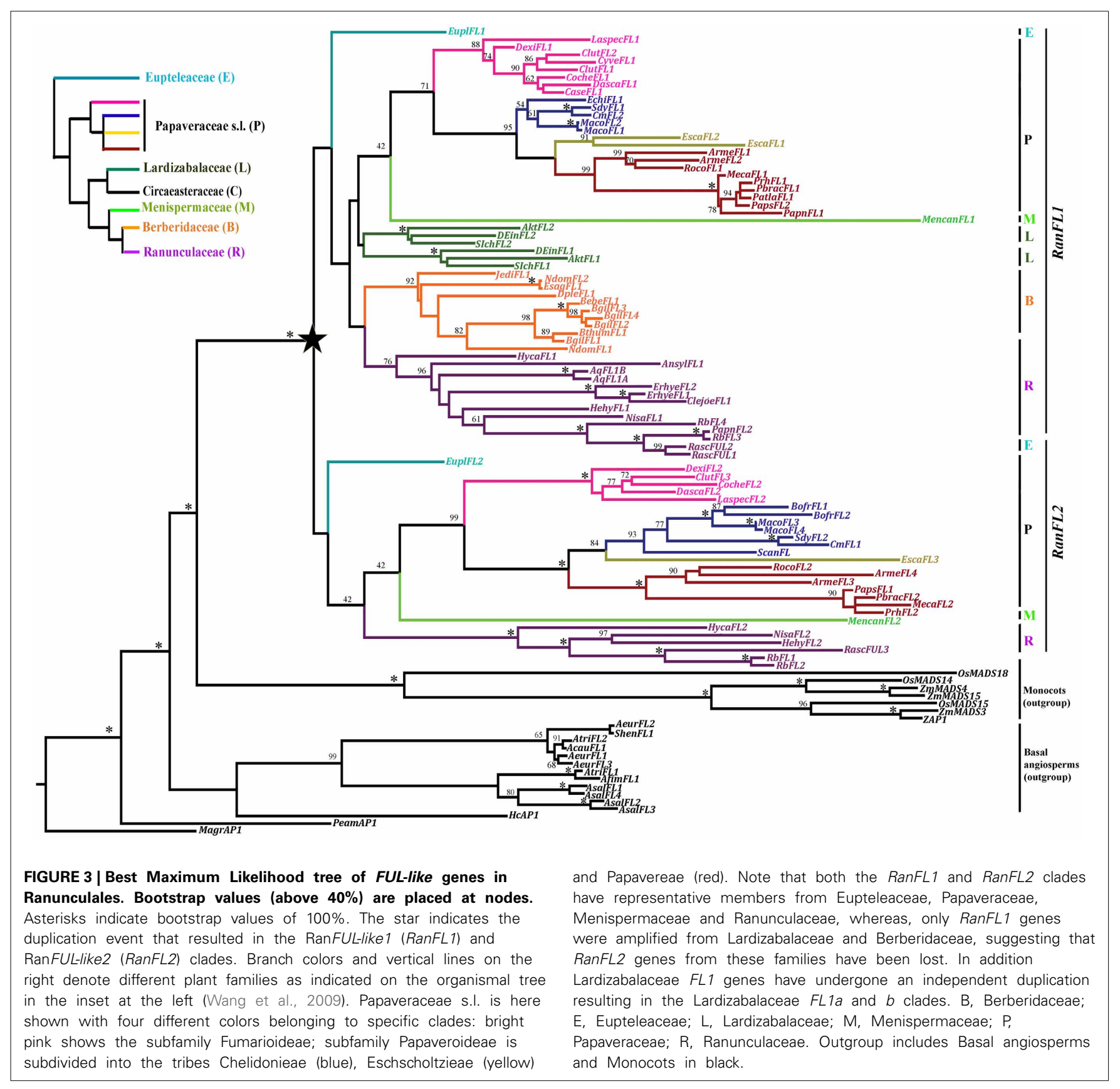

are likely to maintain their functions and partners, given that during polyploidization events their partners also duplicate (Otto and Whitton, 2000; Blanc and Wolfe, 2004). Duplicates in E. californica are likely tandem-repeats or transcripts inserted by retro-transposition, as this is thought to be a diploid species with a chromosome number of $2 n=14$ (Hidalgo et al., in prep). Similar local FUL-like gene duplications may have occurred in E. hyemalis and R. bulbosus, which are also thought to be diploids $(2 n=16$; Index to Plant Chromosome Numbers; Missouri Botanical Garden, http://www.tropicos.org/Project/IPCN).

Taxon-specific losses are harder to confirm, since is possible that some copies were not recovered through our cloning strategy. Nevertheless, our results suggest that RanFL1 copies were lost in
Sanguinaria canadensis and B. frutescens (Papaveraceae s.str.), and that RanFL2 copies were lost in Cysticapnos vesicaria, Capnoides sempervirens and Eomecon chionanta (Papaveraceae s.l.) as well as in Anemone sylvestris, E. hyemalis, Clematis sp and A. coerulea (Ranunculaceae). The loss can only be confirmed in the case of A. coerulea as in this case the genome has been sequenced (Joint Genome Institute, 2010).

Finally we identified amino acid synapomorphies for subclades within the RanFL1 and RanFL2 subclades, but no synapomorphies for those two clades themselves, consistent with the low support values in the deeper branches of the tree (Figures 3, 4). Nearly all the terminal subclades have at least one synapomorphy or as many as nine, however, the number of synapomorphies 
for each paralogous subclade differs greatly according to the family. For instance whereas Papaveraceae s. str. FL1 and FL2 have a single synapomorphy supporting each clade, Ranunculaceae FL1 and FL2 have one and nine synapomorphies respectively, suggesting that conserved aminoacids may have been fixed at different rates in the coding sequences of different paralogous clades.

\section{SHIFTS IN SELECTION CONSTRAINTS IN THE HISTORY OF RANUNCULALES FUL-like GENES}

Likelihood ratio tests, carried out to determine whether there were differences in selection acting on the ranunculid FUL-like sequences, show all tested ranunculid lineages to have $\omega<1$, indicating purifying selection (Table 1). This purifying pressure, however, exhibits significant variation (strengthening and release) across FUL-like subclades and in different protein domains (Figure 5A; Table 1). Indeed, while Ranunculales do not show a significant difference in the selective pressure acting on FUL proteins with respect to background taxa (basal angiosperms and grasses) at the level of the whole sequence, purifying pressure is significantly reinforced in the MADS domain and released in the IK region. In addition the analyses revealed that although both gene clades are under purifying selection, the degree of purifying selection is stronger in RanFL1 $\left(\omega_{f}=0.18\right.$ vs. $\left.\omega_{b}=0.25\right)$ and significantly relaxed in RanFL2 $\left(\omega_{b}=0.29\right.$ vs. $\left.\omega_{0}=0.19\right)$ (Figure 5A, $\omega_{f}$ vs. $\omega_{b}$ values and statistical significance are listed in Table 1).

An expanded analysis using the two-ratio test in each gene subclade showed a more complicated pattern of molecular evolution with each plant family showing unique selection constraints. Strengthening of purifying selection is detected in Papaveraceae s.l. FL1 and Berberidaceae FL1 $\left(\omega_{f}=0.13\right.$ vs. $\omega_{b}=0.23$ and $\omega_{f}=0.15$ vs. $\omega_{b}=0.22$ respectively), whereas purifying selection is relaxed in Lardizabalaceae FLla $\left(\omega_{f}=0.46\right.$ vs. $\omega_{b}=$ $0.21)$ and FL1b $\left(\omega_{f}=0.33\right.$ vs. $\left.\omega_{b}=0.21\right)$, Papaveraceae FL2 $\left(\omega_{f}=0.30\right.$ vs. $\left.\omega_{b}=0.19\right)$ and Ranunculaceae FL2 ( $\omega_{f}=0.21$ vs. $\left.\omega_{b}=0.27\right)$. In addition, these analyses also detected strong purifying selection in Menispermaceae FL1 and FL2 ( $\omega_{f}=0.16$ vs. $\omega_{b}=0.21$ and $\omega_{f}=0.16$ vs. $\omega_{b}=0.21$ respectively) as well as relaxed purifying selection in Eupteleaceae FL1 and FL2 $\left(\omega_{f}=\right.$ 0.30 vs. $\omega_{b}=0.21$ and $\omega_{f}=0.36$ vs. $\omega_{b}=0.21$ respectively), however, significant statistical support is lacking in these cases (Figure 5A; Table 1).

In order to test whether specific regions of the proteins were experiencing different selective pressures, we repeated the tests on the three distinct protein regions: the MADS (1-180 nt), the I $+\mathrm{K}$ (181-541 nt) and the C-terminal (542-910 nt) domains. The results showed that the MADS domain was under strong purifying selection in the Papaveraceae s.l. FL1 $\left(\omega_{f}=\right.$ 0.01 vs. $\left.\omega_{b}=0.05\right)$ and under relaxed purifying selection in Lardizabalaceae FL1a and FL1b $\left(\omega_{f}=0.26\right.$ vs. $\omega_{b}=0.04$ and $\omega_{f}=0.22$ vs. $\omega_{b}=0.04$ respectively) and in the Eupteleaceae FL2 $\left(\omega_{f}=0.19\right.$ vs. $\left.\omega_{b}=0.04\right)$. Changes in selection were also evident in the $\mathrm{I}+\mathrm{K}$ domains, showing strong purifying selection in Papaveraceae s.l. FL1 $\left(\omega_{f}=0.08\right.$ vs. $\left.\omega_{b}=0.19\right)$ and Berberidaceae FL1 $\left(\omega_{f}=0.08\right.$ vs. $\left.\omega_{b}=0.18\right)$ and a relaxed purifying selection in Eupteleaceae FL1 and FL2 ( $\omega_{f}=0.47$ vs. $\omega_{b}=$ 0.16 and $\omega_{f}=0.43$ vs. $\left.\omega_{b}=0.17\right)$, Lardizabalaceae FLla $\left(\omega_{f}=\right.$ 0.67 vs. $\left.\omega_{b}=0.16\right)$, Papaveraceae FL2 $\left(\omega_{f}=0.28\right.$ vs. $\left.\omega_{b}=0.15\right)$ and Ranunculaceae FL2 $\left(\omega_{f}=0.33\right.$ vs. $\left.\omega_{b}=0.16\right)$. Significative changes in selection at the $\mathrm{C}$ terminus were only detected in Papaveraceae s.l. ( $\omega_{f}=0.62$ vs. $\left.\omega_{b}=0.39\right)$ (Figure 5A; Table 1).

\section{DISCUSSION \\ FUL-like GENES UNDERWENT DUPLICATION EARLY IN THE DIVERSIFICATION OF THE RANUNCULALES}

The ML analysis showed a single major duplication in the ranunculid FUL-like genes which gave rise to the RanFL1 and RanFL2 gene clades early in the diversification of the order

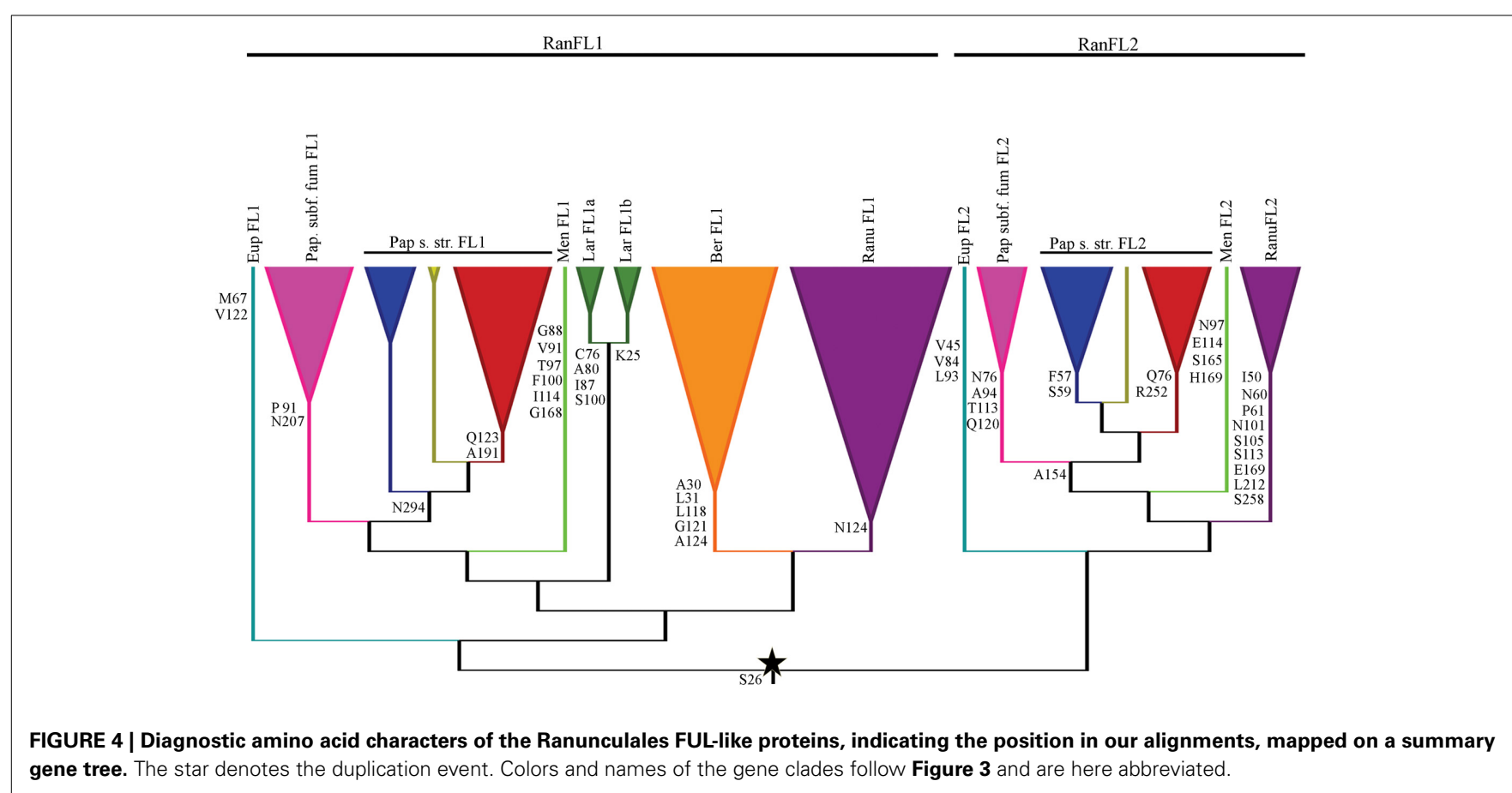




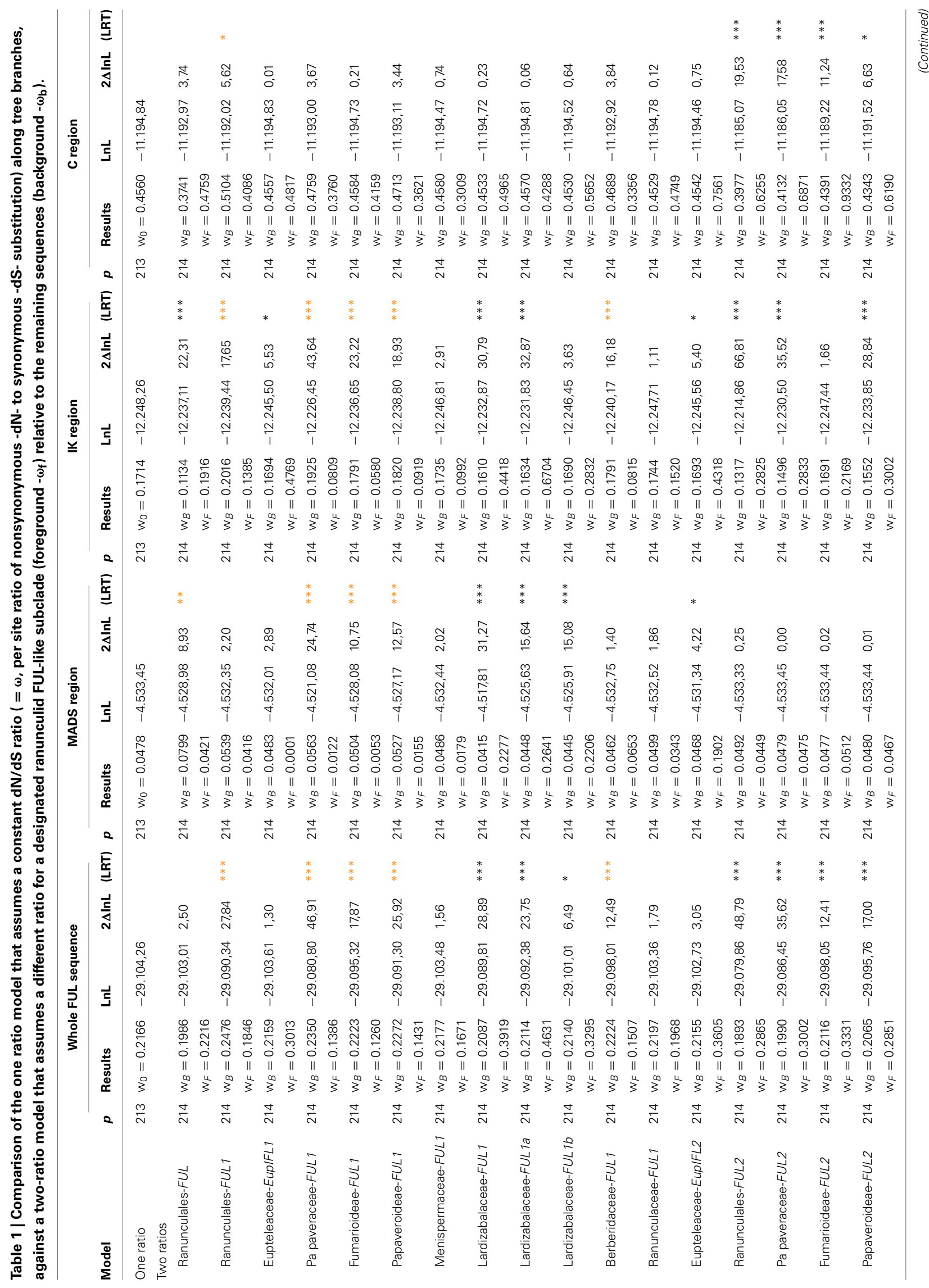




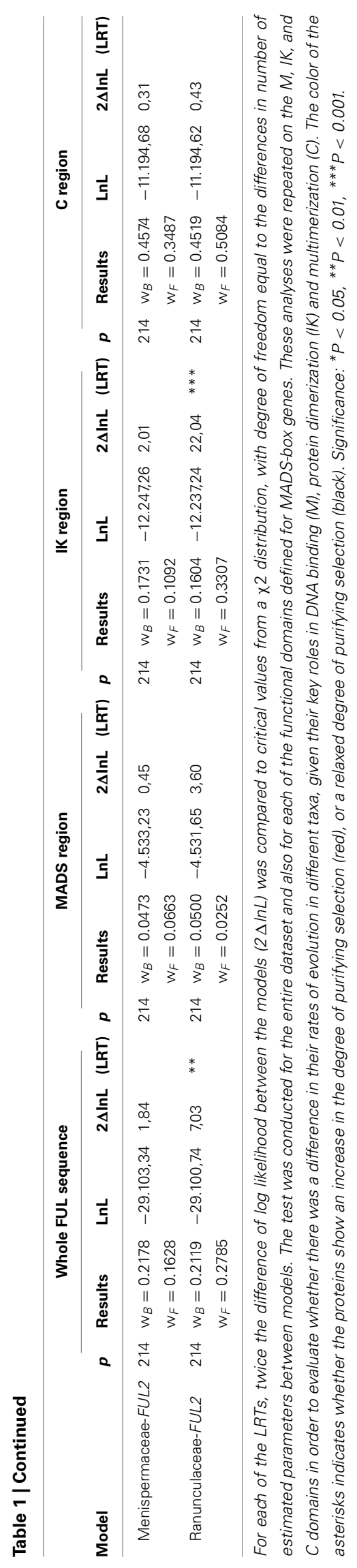

Ranunculales. This duplication was not recovered in previous analyses of the AP1/FUL gene lineage (Litt and Irish, 2003; Shan et al., 2007). Although these analyses suggested major duplications occurred in the FUL-like genes in Ranunculales, it was not clear when they occurred. Our analyses on an expanded sample of Ranunculales clearly established that there was a single major event very early in the diversification of the order, however, is still unclear whether this duplication occurred before or after the divergence of Eupteleaceae. In fact, low support within each major clade and high similarity between EUplFL1 and EUplFL2 suggest that an alternative topology to Figure 3 tree would be possible, in which two independent duplications occurred, one within the Eupteleaceae and another after the divergence of the Eupteleaceae but before the diversification of all other Ranunculiids. This would be similar to the scenario found in the reconstruction of the evolutionary history of the APETALA3 (AP3) genes in the Ranunculales, in which three duplications occurred: one in the Eupteleaceae and two in the remaining Ranunculales (Sharma et al., 2011). This indication that FUL-like and AP3 genes underwent duplication events early in the diversification of most Ranunculales, before or right after the split of Eupteleaceae, suggests a possible ancestral genome-wide polyploidization event (Cui et al., 2006) in the Ranunculales, independent to the already wellestablished gamma-duplication in the core eudicots (Jiao et al., 2011; Vekemans et al., 2012).

In addition, whereas RanFL1 genes are found in all the families of the order sampled so far, RanFL2 genes were not found in Lardizabalaceae and Berberidaceae. This may be because in those two families our primers did not pick up RanFL2 genes, or those genes are not expressed in leaf or floral tissue, or they were lost. None of these hypotheses can be rejected at this time, but after numerous amplification attempts with multiple degenerate primers specifically targeted to RanFL2 genes, as well as extensive database searches, we favor the second and the third.

The clarification of orthology and paralogy of previously functionally characterized FUL-like genes sheds light on why these FUL-like genes might have both overlapping and unique functions (Figure 1). Our results show that PapsFL2 and EscaFL1 and EscaFL2 are orthologs belonging to the RanFL1 clade (Figure 3). On the other hand, PapsFL1 is orthologous to EscaFL3, which was not discovered in previous studies in E. californica (Figure 3). These latter two genes belong to the RanFL2 clade. These results suggest that the reason escafll-fl2 double mutants in E. californica did not show defects in cauline leaf development, flowering time and petal identity as did papsfli-fl2 mutants may be because EscaFL3 is redundant for these functions (Pabón-Mora et al., 2012). Our results also confirm that the two A. coerulea FUL-like copies are the result of an independent duplication, as AqcFL1A and AqcFL1B are recent paralogs belonging to the RanFL1 clade. RanFL2 copies are not present in the Aquilegia genome. This gene loss may explain why results from functional analyses in poppies could not be extrapolated to Aquilegia (Pabón-Mora et al., 2012, 2013), and indeed probably suggests results from Aquilegia cannot even be applied to other members of Ranunculaceae. Gene loss in Aquilegia might have resulted in 
A

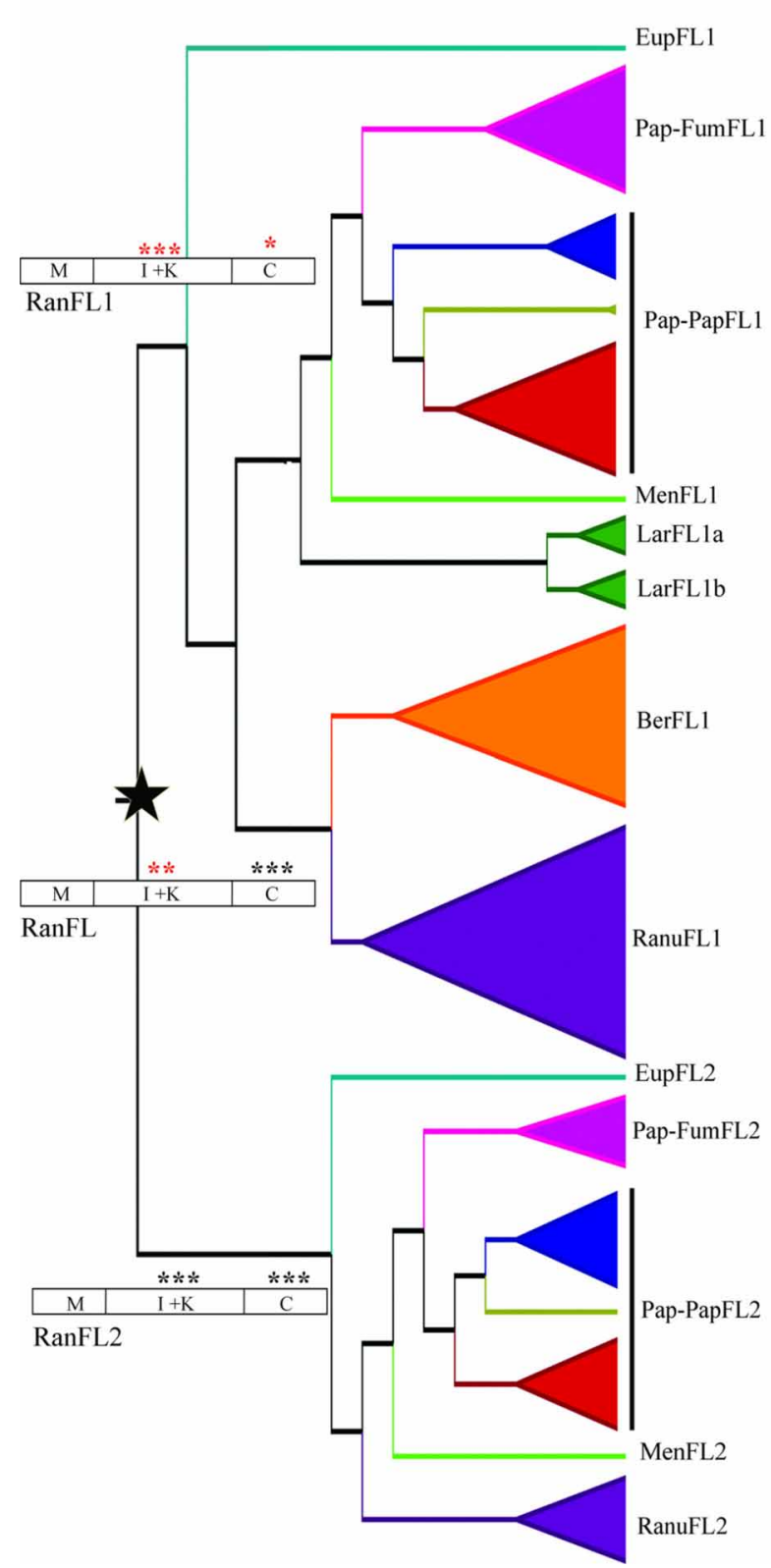

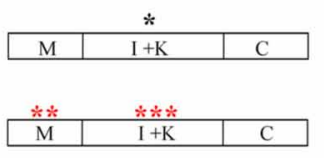
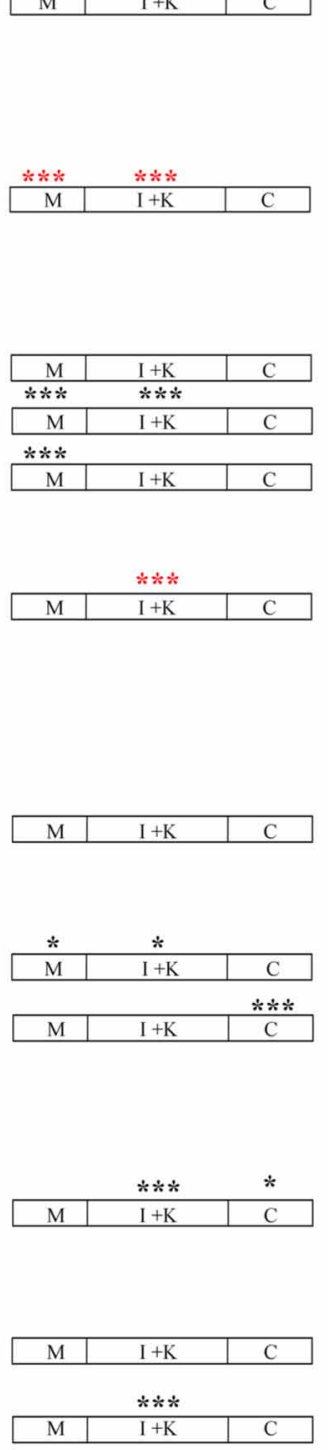

B

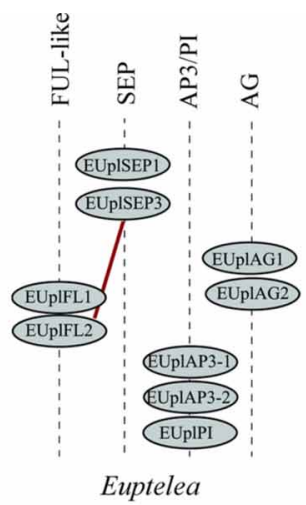

(Eupteleaceae)

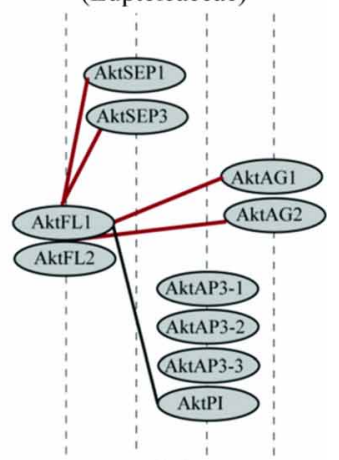

Akebia

(Lardizabalaceae)

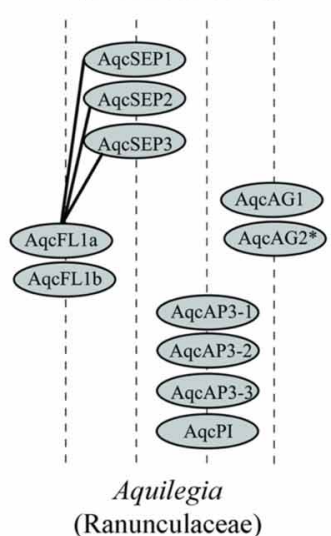

FIGURE $\mathbf{5}$ | (A) Changes in selection constraint in the ranunculid FUL-like lineage inferred by the CodeML program of PAML. The star denotes the duplication event. The protein structure has been diagramed to show the MADS-box (M), the I and $K(I+K)$, and the C-terminal (C) domains. The two-ratio model was tested on all ranunculid genes, the RanFL1 and RanFL2 clades, and all the subclades. Asterisks indicate which genes and which regions of the protein have a significantly better fit under the two-ratio model. The color of the asterisks indicates whether the proteins show an increase in the degree of purifying selection (red), or a relaxed degree of purifying selection (black). Significance: ${ }^{*} P<0.05,{ }^{* *} P<0.01,{ }^{* * *} P<0.001$. (B) Summary of the reported protein interactions of ranunculid FUL-like genes with SEPALLATA (SEP), APETALA3/PISTILLATA (AP3/PI) and AGAMOUS (AG) floral organ identity proteins. Solid red lines indicate that both FUL-like copies were tested and had the same interactions. Solid black lines indicate that only that particular FUL-like copy was tested. Interactions are those reported in Liu et al. (2010) and Pabón-Mora et al. (2013). the rewiring of flower and fruit developmental networks such that FUL-like genes are excluded from roles in floral meristem identity, floral organ identity, or fruit development, and instead have been co-opted into leaf development. Nevertheless, it is also possible that AqcFL1 residual transcript, or redundancy with other transcription factors masked the roles of AqcFL1 genes in flower and fruit development in previous experiments (Pabón-Mora et al., 2013). 


\section{SEQUENCE CHANGES IN THE C-TERMINAL DOMAIN RESULTED IN NEW MOTIFS THAT MIGHT PLAY ROLES IN ACTIVATION AND PROTEIN MULTIMERIZATION CAPABILITIES}

We have shown that ranunculid FUL-like proteins have, at the beginning of the $\mathrm{C}$ terminal domain, glutamine-rich segments carrying from 3 to 9 consecutive glutamines (Q) and 3-4 nonconsecutive glutamines. Glutamine-rich motifs are also found in grass FUL-like proteins (Preston and Kellogg, 2006), and glutamine-rich domains in plants, carrying from 4 to 20 repeats, have been known to behave as transcription activation domains (Gerber et al., 1994; Schwechheimer et al., 1998; Xiao and Jeang, 1998; Wilkins and Lis, 1999; Immink et al., 2009); this suggests that FUL-like proteins may have transcription activation capability similar to euAP1 proteins (Cho et al., 1999). However, AqFL1A and AqFL1B (with 2 consecutive and 2 non-consecutive Q), as well as PapsFL1 and PapsFL2 (both with 4 consecutive Q) have not been shown to auto-activate in yeast systems (Pabón-Mora et al., 2012, 2013). Other ranunculid FL proteins, like those of Eschscholzia, have a larger number of glutamines but have not yet been tested for transcription activation capability. Glutamine repeats in eukaryotes have also been hypothesized to behave as "polar zippers" in protein-protein interactions (Perutz et al., 1994; Michleitsch and Weissman, 2000), thus these regions might mediate strength and specificity of FUL-like protein interactions.

This study identified two additional protein regions conserved in ranunculid FUL-like proteins including the sequence QNS$\mathrm{P} / \mathrm{LS} / \mathrm{TFLLSQSE} / \mathrm{LP}-\mathrm{SLN} / \mathrm{TI}$, and a negatively charged region rich in glutamic acid (E) before the conserved FUL-motif LMPPWML (Figure 2). There are no functional studies specific for these regions, however, it has been shown that the N/SS at positions 227-228 are consistently found in AP1/FUL proteins and shared with SUPPRESSOR OF OVEREXPRESSION OF CONSTANS 1 (SOC1) and some SEPALLATA proteins, and that mutations in these amino acids influence interaction specificity and can result in changes in protein partners (Van Dijk et al., 2010).

\section{RELEASE OF PURIFYING SELECTION IN THE I+K PROTEIN DOMAINS MIGHT HAVE INFLUENCED FUNCTIONAL DIVERSIFICATION}

Variation in the rates of evolution of different FUL-like protein regions may also explain the functional differences among characterized proteins in different species. This is based on the premise that the rate of amino acid substitution is limited by functional or structural constraints on proteins (Liu et al., 2008). Previous studies have shown that differences in the rates and patterns of molecular evolution appear to be associated with divergence of developmental function between paralogous MADS-box loci (Lawton-Rauh et al., 1999). A common way to measure changes in protein sequence evolution is the $\mathrm{dN} / \mathrm{dS}$ ratio, which calculates the ratio of non-synonymous to synonymous changes in protein sequences and provides an estimate of selective pressure. A dN/dS $<1$ suggests that strong purifying selection has not allowed for fixation of most amino acid substitutions, $\mathrm{dN} / \mathrm{dS}>1$ suggests that constraints are reduced and new amino acids have been able to become fixed due to positive selection, and $\mathrm{dN} / \mathrm{dS}=1$ suggests neutral evolution, in which synonymous changes occur at the same rate as non-synonymous changes and fixation of new amino acids occurs at a neutral rate (Li, 1997; Hurst, 2002).
Our results show that strong purifying selection can be detected in the RanFL1 clade compared to more relaxed purifying selection in the RanFL2 proteins $(p<0.001)$. This would suggest that RanFL2 proteins are evolving at a faster rate, having been released from strong purifying selection after the duplication, and suggests a scenario of long-term maintenance of ancestral functions in one clade (RanFL1) and sub or neo-functionalization in the other clade (RanFL2), (Aagaard et al., 2006). When the same analyses are applied to the subclades within RanFL1 and RanFL2, this pattern can also be seen for the duplicates in Papaveraceae s.l. and Ranunculaceae, but not in other families. For instance a contradictory pattern is found in Lardizabalaceae, in which both FL1a and FL1b proteins (paralogous clades within RanFL1) show relaxed purifying selection, suggesting that within this family, ancestral FUL-like gene functions may have been redistributed among the paralogs or lost, with the potential for new functions to appear in the evolutionary process (Force et al., 1999; Conant and Wagner, 2002).

Our analyses also showed that relaxation in purifying selection occurred preferentially in the $\mathrm{I}+\mathrm{K}$ domains (in Eupteleaceae FL1, FL2, Lardizabalaceae FL1a, FL1b, Papaveraceae s str. FL2 and Ranunculaceae FL2), where dimerization functions have been localized, and less frequently in the MADS domain (in Lardizabalaceae FL1 a and FL1b), important for DNA binding, and the $\mathrm{C}$ terminus (in Papaveraceae s str. FL2), the function of which is not known. Most protein motifs maintained in MADS box duplicates and involved in dimerization occur at a hot-spot at the junction between the MADS and the I domain and is clear that non-synonymous changes in this region can dramatically change protein interactions (Van Dijk et al., 2010). For instance, three spots between the MADS and the I domain are maintained in most MADS box proteins and are thought to control DNA binding, these include Alanine A57, Asparagine N60 and Methionine M61 (Van Dijk et al., 2010). In FUL-like proteins the A57 is replaced by another hydrophobic amino-acid more often Tyrosine Y or Phenylalanine F, the M61 appears in position M63 and is conserved in all sequences, and finally the hydrophobic N60 is maintained in Ranunculaceae FL2, but changed in the rest of RanFL2 and RanFL1 proteins for Aspartic Acid D. The importance of the IK domains in protein-protein interactions has been long recognized. For instance, the end of the I domain and the entire $\mathrm{K}$ domain have been identified as the most important regions for the interactions between FUL-like and SEPALLATA proteins in rice (Moon et al., 1999). Likewise, residues in position 148-158 in APETALA1 seem to be crucial for recovery of floral meristem identity (Alvarez-Buylla et al., 2006) and a point mutation in $\mathrm{Y} 148 \mathrm{~N}$ is known to cause the loss of interaction between AP1 and SEPALLATA4, AGAMOUS-Like6 and AGAMOUSLike15 (Van Dijk et al., 2010). Altogether the data suggests that changes in the IK regions might be key in explaining the different functions reported in ranunculid FUL-like proteins via changes in protein interactions. This is in agreement with observations in paralogous regulatory genes in which relaxed purifying selection is associated with the partitioning or even the acquisition of new interacting protein partners compared to the ancestral (pre-duplication) protein interactions (Dermitzakis and Clark, 2001; see also He and Zhang, 2006; Wagner and Zhang, 2011). 
A comparison of protein-protein interaction data gathered from ranunculid FUL-like proteins and the outgroup Poaceae proteins partially supports this hypothesis. Protein interactions in grasses show that Oryza sativa FUL-like proteins OsMADS14, OsMADS15 and OsMADS18 can only interact with a narrow set of floral organ identity proteins, the SEPALLATA proteins (Moon et al., 1999). Similarly, the Euptelea FUL-like proteins (EuplFL1 and EuplFL2) only interact with SEPALLATA proteins (Liu et al., 2010). The same interactions with floral organ identity proteins have been recorded for Aquilegia (AqFL1a) FUL-like proteins (Pabón-Mora et al., 2013), under strong purifying selection. In contrast, Akebia (Lardizabalaceae) FUL-like proteins, under relaxed purifying selection, appear to have been able to expand the repertoire of protein partners and can interact with SEPALLATA, PISTILLATA and AGAMOUS orthologs (Liu et al., 2010). Clearly more data are required to test the hypothesis that Ranunculales FUL-like protein interactions are maintained under strong purifying selection but diverge under relaxed selection, with resulting diversification of functional outcomes (Figure 5B).

The data presented here and in previous publications (PabónMora et al., 2012, 2013) allow us to hypothesize that: (1) FUL-like genes across ranunculids perform overlapping and unique roles in a manner that cannot be predicted by their expression patterns. (2) Variation in function is possibly due to key amino acid changes in the I and $\mathrm{K}$ domains, important in dimerization, as well as unique protein motifs in the C-domain likely important for multimerization. In combination, these might have provided FUL-like homologs in the Ranunculales with different biochemical capabilities and protein interactions. (3) Understanding the evolution of gene pleiotropy in terms of protein regions that might be important for different functions in pre-duplication FUL-like genes across basal eudicots, provides clues on how FUL-like genes might have taken on different roles. Future

\section{REFERENCES}

Aagaard, J. E., Willis, J. H., and Phillips, P. C. (2006). Relaxed selection among duplicate floral regulatory genes in Lamiales. J. Mol. Evol. 63, 493-503. doi: 10.1007/s00239005-0306-x

Akaike, H. (1974). A new look at the statistical model identification. IEEE Trans. Automat. Contr. 19, 716-723. doi: 10.1109/TAC.1974. 1100705

Altschul, S. F., Gish, W., Miller, W., Myers, E. W., and Lipman, D. J. (1990). Basic local alignment search tool. J. Mol. Biol. 215, 403-410. doi: 10.1006/jmbi.1990.9999

Alvarez-Buylla, E. R., García-Ponce, B., and Garay-Arroyo, A. (2006). Unique and redundant functional domains of APETALA1 and CAULIFLOWER, two recently duplicated Arabidopsis thaliana floral MADS-box genes. J. Exp. Bot. 57, 3099-3107. doi: 10.1093/jxb/erl081

APG. (2009). An update of the Angiosperm Phylogeny Group classification for the orders and families of flowering plants: APG III. Bot. J. Linn. Soc. 161, 105-121. doi: $\quad 10.1111 /$ j.1095-8339.2009.00 996.x

Barker, M. S., Vogel, H., and Schranz, M. E. (2009). Paleopolyploidy in the Brassicales: analyses of the Cleome transcriptome elucidate the history of genome duplications in Arabidopsis and other Brassicales. Genome Biol. Evol. 1, 391-399. doi: 10.1093/gbe/evp040

Bemer, M., Karlova, R., Ballester, A. R., Tikunov, Y. M., Bovy, A. G., Wolters-Arts, M., et al. (2012). The tomato FRUITFULL homologs TDR4/FUL1 and MBP7/FUL2 regulate ethyleneindependent aspects of fruit doi: 10.1105/tpc. 112.103283

Benlloch, R., d'Erfurth, I., Ferrandiz, C., Cosson, V., Beltrán, J. P., Cañas, L. A., et al. (2006). Isolation of mtpim proves Tnt 1 a useful reverse genetics tool in Medicago truncatula ripening. Plant Cell 24, 4437-4451. directions include expression analyses and functional characterization of FUL-like genes in other Ranunculales, tests on the protein interactions between FUL-like proteins and other floral organ identity proteins in different ranunculid taxa, and functional characterization of the conserved motifs, particularly at the IK domains and the C-terminus.

\section{ACKNOWLEDGMENTS}

We thank the issue editors for inviting us to write a manuscript in this special issue. This work was supported by the US National Science Foundation (grant number IOS-0923748), the Fondo de apoyo al Primer Proyecto 2012 to Natalia Pabón-Mora, and the Estrategia de Sostenibilidad 2013-2014 at the Universidad de Antioquia (Medellín-Colombia). Oriane Hidalgo benefitted from a "Juan de la Cierva" contract (JCI-2010-07516).

\section{SUPPLEMENTARY MATERIAL}

The Supplementary Material for this article can be found online at: http://www.frontiersin.org/Plant_Evolution_and_Development/ 10.3389/fpls.2013.00358/abstract

Figure S1 | K-domain sequence alignment of ranunculid FUL-like proteins. Hydrophobic amino-acids in the a and d positions in the heptad repeats $(a b c d e f g)_{n}$ are in bold. The predicted protein sequence at this domain contains three amphipathic $\alpha$-helices: K1, K2, and K3. Within K1, positions $99(E), 102(K), 104(K)$ are conserved in all ranunculid sequences and the outgroup, except for Mencan1 y Mencan2. Similarly, positions 106 (K), 108 (E) are also conserved, except in RocoFL2, ArmeFL4. Finally $111(\mathrm{Q})$ is also conserved except in MacoFL3, MacoFL4. Within K2 positions 119 (G), 128 (K), $129(E), 134$ (E), $136(\mathrm{Q})$ are conserved except in ArmeFL3. Conserved hydrophobic amino-acids outside of the predicted helices are highlighted and labeled with $\mathrm{h}$.

Table S1 | Accession numbers of FUL-like sequences used in this study. and uncovers new aspects of AP1-like functions in legumes. Plant Physiol. 142, 972-983. doi: $10.1104 / \mathrm{pp} \cdot 106.083543$

Berbel, A., Ferrandiz, C., Hecht, V., Dalmais, M., Lund, O. S., Sussmilch, F. C., et al. (2012). VEGETATIVE1 is essential for development of the compound inflorescence in pea. Nat. Commun. 3 797. doi: 10.1038/ncomms 1801

Berbel, A., Navarro, C., Ferrandiz, C., Cañas, L. A., Madueño, F., and Beltrán, J. (2001). Analysis of PEAM4, the pea AP1 functional homologue, supports a model for AP1-like genes controlling both floral meristem and floral organ identity in different plant species. Plant J. 25, 441-451. doi: 10.1046/j.1365313x.2001.00974.x

Blanc, G., Hokamp, K., and Wolfe, K. H. (2003). A recent polyploidy superimposed on older large scale duplications in the Arabidopsis genome. Genome Res. 13, 137-144. doi: $10.1101 /$ gr.751803
Blanc, G., and Wolfe, K. H. (2004). Functional divergence of duplicated genes formed by polyploidy during Arabidopsis evolution. Plant Cell 16, 1679-1691. doi: 10.1105/tpc.021410

Bowers, J. L., Chapman, B. A., Rong, J., and Paterson, A. H. (2003). Unravelling angiosperm genome evolution by phylogenetic analysis of chromosomal duplication events. Nature 422, 433-438. doi: 10.1038/nature01521

Bowman, J., Alvarez, J., Weigel, D., Meyerowitz, E. M., and Smyth, D. R. (1993). Control of flower development in Arabidopsis thaliana by APETALA1 and interacting genes. Development 119, 721-743.

Burko, Y., Shleizer-Burko, S., Yanai, O., Shwartz, I., Zelnik, I. D., JacobHirsch, J., et al. (2013). A role for APETALA1/FRUITFULL transcription factors in tomato leaf development. Plant Cell 25, 2070-2083. doi: 10.1105/tpc.113.113035

Castillejo, C., Romera-Branchat, M., and Pelaz, S. (2005). A new role of 
the Arabidopsis SEPALLATA3 gene revealed by its constitutive expression. Plant J. 43, 586-596. doi: 10.1111/j.1365-313X.2005.02476.x

Cho, S., Jang, S., Chae, S., Chung, K. M., Moon, Y., An, G., et al. (1999). Analysis of the C-terminal region of Arabidopsis thaliana APETALA1 as a transcription activation domain. Plant Mol. Biol. 40, 419-429. doi: 10.1023/A:1006273127067

Coen, E., and Meyerowitz, E. M. (1991). The war of the whorls: genetic interactions controlling flower development. Nature 353, 31-37. doi: 10.1038/353031a0

Conant, G., and Wagner, A. (2002). Asymmetric sequence divergence of duplicate genes. Genome Res. 13, 2052-2058. doi: 10.1101/gr.1252603

Cui, L., Wall, P. K., Leebens-Mack, J., Lindsay, B. G., Soltis, D. E., and Doyle, J. J. (2006). Widespread genome duplications throughout the history of flowering plants. Genome Res. 16, 738-749. doi: 10.1101/gr.4825606

Dermitzakis, E., and Clark, A. (2001). Differential selection after duplication in mammalian developmental genes. Mol. Biol. Evol. 18, 557-562. doi: 10.1093/oxfordjournals.molbev.a003835

Ferrándiz, C., Gu, Q., Martienssen, R., and Yanofsky, M. F. (2000). Redundant regulation of meristem identity and plant architecture by FRUITFULL, APETALA1 and CAULIFLOWER. Development 127, 725-734.

Force, A., Lynch, M., Pickett, F., Amores, A., Yan, Y., and Postlehwait, J. (1999). Preservation of duplicate genes by complementary degenerative mutations. Genetics 151, 1531-1545.

Gerber, H. P., Seipel, K., Georgiev, O., Hofferer, M., Hug, M., Rusconi, S., et al. (1994). Transcriptional activation modulated by homopolymeric glutamine and proline stretches. Science 263, 808-811. doi: $10.1126 /$ science. 8303297

Gu, Q., Ferrandiz, C., Yanofsky, M. F., and Martienssen, R. (1998). The FRUITFULL MADS-box gene mediates cell differentiation during Arabidopsis fruit development. Development 125, 1509-1517.

Gustafson-Brown, C., Savidge, B., and Yanofsky, M. F. (1994). Regulation of the Arabidopsis floral homeotic gene APETALA1. Cell 76, 131-143. doi: 10.1016/0092-8674 (94)90178-3

He, X., and Zhang, J. (2006). Toward a molecular understanding of pleiotropy. Genetics 173, 1885-1891. doi: 10.1534/genetics.106.060269
Huijser, P., Klein, J., Lonnig, W-E., Meijer, H., Saedler, H., and Sommer, H. (1992). Bracteomania, an inflorescence anomaly, is caused by the loss of function of the MADSbox gene squamosa in Antirrhinum majus. ЕМВО J. 11, 1239-1249.

Hurst, L. D. (2002). The Ka/Ks ratio: diagnosing the form of sequence evolution. Trends Genetics 18, 486. doi: 10.1016/S0168-9525(02) 02722-1

Immink, R. G. H., Hannapel, D. J., Ferrario, S., Busscher, M., Franken, J., Lookeren-Campagne, M. M., et al. (1999). A petunia MADS box gene involved in the transition from vegetative to reproductive development. Development 126, 5117-5126.

Immink, R. G. H., Tonaco, I. A. N., deFolter, S., Shchennikova, A. vanDijk, A. D. J., Busscher-Lange, J., et al. (2009). SEPALLATA3: the 'glue' for MADS box transcription factor complex formation. Genome Biol. 10:R24. doi: 10.1186/gb-200910-2-r24

Irish, V. F., and Sussex, I. M. (1990). Function of the apetala-1 gene during Arabídopsis floral development. Plant Cell 2, 741-753. doi: $10.2307 / 3869173$

Jaakola, L., Poole, M., Jones, M. O., Kamarainen-Karppinen, T., Koskimaki, J. J., Hohtola, A., et al. (2010). A SQUAMOSA MADS box gene is involved in the regulation of anthocyanin accumulation in bilberry fruits. Plant Physiol. 153, 1619-1629. doi: 10.1104/pp.110.158279

Jiao, Y., Wickett, N. J., Ayyampalayam, S., Chanderbali, A. S., Landherr, L., Ralph, P. E., et al. (2011). Ancestral polyploidy in seed plants and angiosperms. Nature 473, 97-100. doi: 10.1038/nature09916

Joint Genome Institute. (2010). Phytozome v6.0. Avilable online at: http://www.phytozome.net/

Katoh, K., Misawa, K., Kuma, K., and Miyata, T. (2002). MAFFT: a novel method for rapid multiple sequence alignment based on a fast Fourier transform. Nucleic Acids Res. 30 , 3059-3066. doi: 10.1093/nar/gkf436

Kempin, S., Savidge, B., and Yanofsky, M. F. (1995). Molecular basis of the cauliflower phenotype in Arabidopsis. Science 27, 522-525. doi: 10.1126/science.7824951

Kobayashi, K., Yasuno, N., Sato, Y., Yoda, M., Yamazaki R., Kimizu, M., et al. (2012). Inflorescence meristem identity in rice is specified by overlapping functions of three AP1/FUL-like MADS box genes and PAP2, a SEPALLATA MADS box gene. Plant Cell 24, 1848-1859. doi: 10.1105/tpc.112.097105

Lawton-Rauh, A. L., BucklerIV, ES, and Purugganan, M. D. (1999). Patterns of molecular evolution among paralogous floral homeotic genes. Mol. Biol. Evol. 16, 1037-1045. doi: 10.1093/oxfordjournals.molbev.a026193

Li, W.-H. (1997). Molecular Evolution. Sunderland, MA: Sinauer Associates.

Litt, A., and Irish, V. F. (2003) Duplication and diversification in the APETALA1/FRUITFULL floral homeotic gene lineage: implications for the evolution of floral development. Genetics 165, 821-833.

Liu, C., Zhang, J., Zhang, N., Shan, H., Su, K., Zhang, J., et al. (2010). Interactions among proteins of floral MADS-box genes in basal eudicots: implications for evolution of the regulatory network for flower development. Mol. Biol. Evol. 27, 1598-1611. doi 10.1093/molbev/msq044

Liu, J., Zhang, Y., Leu, X., and Zhang, Z. (2008). Natural selection of protein structural and functional properties: a single nucleotide polymorfism perspective. Genome Biol. 9, R69. doi:10.1186/gb-2008-9-4-r69

Maddison, D. R., and Maddison, W. P. (2005). MacClade 4: analysis of phylogeny and character evolution. Version 4.08a. Avilable online at: http://macclade.org

Mandel, M. A., and Yanofsky, M. F. (1995). The Arabidopsis AGL8 MADS box gene is expressed in inflorescence meristems and is negatively regulated by APETALA1. Plant Cell 7, 1763-1771.

Melzer, S., Lens, F., Gennen, J. Vanneste, S., Rohde, A., and Beeckman, T. (2008). Floweringtime genes modulate meristem determinacy and growth form in Arabidopsis thaliana. Nat. Genetics 40, 1489-1492. doi: 10.1038/ng.253 Michleitsch, M., and Weissman, J. (2000). A census of glutamine/asparagine-rich regions: implications for their conserved function and the prediction of novel prions. Proc. Natl. Acad. Sci. U.S.A. 97, 11910-11915. doi: 10.1073/pnas.97.22.11910

Miller, M. A., Holder, H. T., Vos, R., Midford, P. E., Liebowitz, T., Chan, L., et al. (2009). The CIPRES portals. Avilable online at: http://www. phylo.org

Moon, Y.-H., Hang, H.-G., Jung, J.Y., Jeon, J.-S., Sung, S.-K., and An, G. (1999). Determination of the motif responsible for interaction between the rice APETALA1/
AGAMOUS-LIKE9 family proteins using a yeast two-hybrid System. Plant Physiol. 120, 1193-1203. doi: 10.1104/pp.120.4.1193

Müller, B. M., Saedler, H., and Zachgo, S. (2001). The MADS-box gene DEFH28 from Antirrhinum is involved in the regulation of floral meristem identity and fruit development. Plant J. 28, 169-179. doi: 10.1046/j.1365-313X. 2001.01139.x

Murai, K., Miyamae, M., Kato, H., Takumi, S., and Ogihara, Y. (2003). WAP1, a wheat APETALA1 homolog, plays a central role in the phase transition from vegetative to reproductive growth. Plant Cell Physiol. 44, 1255-1265. doi: $10.1093 / \mathrm{pcp} / \mathrm{pcg} 171$

Otto, S. P., and Whitton, J. (2000). Polyploid incidence and evolution. Annu. Rev. Genet. 34, 401-437. doi: 10.1146/annurev.genet.34.1.401

Pabón-Mora, N., Ambrose, B. A., and Litt, A. (2012). Poppy APETALA1/FRUITFULL orthologs control flowering time, branching, perianth identity, and fruit development. Plant Physiol. 158, 1685-1704. doi: 10.1104/pp.111. 192104

Pabón-Mora, N., Sharma, B., Holappa, L., Kramer, E., and Litt, A. (2013). The Aquilegia FRUITFULL-like genes play key roles in leaf morphogenesis and inflorescence development. Plant J. 74, 197-212. doi: $10.1111 /$ tpj.12113

Parenicová, L., deFolter, S., Kieffer, M. Horner, D. S., Favalli, C., Busscher, J., et al. (2003). Molecular and phylogenetic analyses of the complete MADS-box transcription factor family in Arabidopsis: new openings to the MADS world. Plant Cell 15, 1538-1551. doi: 10.1105/ tpc. 011544

Perutz, M., Johnson, T., Suzuki, M. and Finch, J. (1994). Glutamine repeats as polar zippers: their possible role in inherited neurodegenerative diseases. Proc. Natl. Acad. Sci. U.S.A. 91, 5355-5358. doi: 10.1073/pnas.91.12.5355

Posada, D., and Crandall, K. A. (1998). MODELTEST: testing the model of DNA substitution. Bioinformatics 14, 817-818. doi: 10.1093/bioinformatics/14.9.817

Preston, J. C., and Kellogg, E. A. (2006). Reconstructing the evolutionary history of paralogous APETALA1/FRUITFULL-like genes in grasses (Poaceae). Genetics 174, 421-437. doi: 10.1534/genetics. 106 . 057125

Purugganan, M. D., and Suddith, J. I. (1998). Molecular population 
genetics of the Arabidopsis CAULIFLOWER regulatory gene: nonneutral evolution and naturally occurring variation in floral homeotic function. Proc. Natl. Acad. Sci. U.S.A. 96, 8130-8134. doi: 10.1073/pnas.95. 14.8130

Schwechheimer, C., Smith, C., and Bevan, M. W. (1998). The activities of acidic and glutamine-rich transcriptional activation domains in plant cells: design of modular transcription factors for high level expression Plant Mol. Biol. 36, 195-204. doi: 10.1023/A:100599032 1918

Shan, H., Zhang, N., Liu, C., Xu, G., Zhang, J., Chen, Z., et al. (2007). Patterns of gene duplication and functional diversification during the evolution of the AP1/SQUA subfamily of plant MADS-box genes. Mol. Phylogenet. Evol. 44, 26-41. doi: 10.1016/j.ympev.2007. 02.016

Sharma, B., Guo, C., Kong, H., and Kramer, E. M. (2011). Petalspecific subfunctionalization of an APETALA3 paralog in the Ranunculales and its implications for petal evolution. New Phytol. 191, 870-883. doi: 10.1111/j.1469-8137. 2011.03744.x

Smaczniak, C., Immink, R. G. H., Muiño, J. M., Blanvillain, R., Busscher, M., Busscher-Lange, J., et al. (2012). Characterization of MADS-domain transcription factor complexes in Arabidopsis flower development. Proc. Natl. Acad.
Sci. U.S.A. 109, 1560-1565. doi: 10.1073/pnas.1112871109

Stamatakis, A., Hoover, P., and Rougemont, J. (2008). A fast bootstrapping algorithm for the RAxML web-servers. Syst. Biol. 57, 758-771. doi: 10.1080/106351508 02429642

Torti, S., Fornara, F., Vincent, C., Andrés, F., Nordström, K., Göbel, U., et al. (2012). Analysis of the Arabidopsis shoot meristem transcriptome during floral transition identifies distinct regulatory patterns and a leucine-rich repeat protein that promotes flowering. Plant Cell 24, 444-462. doi: 10.1105/tpc.111.092791

Van Dijk, A. D. J., Morabito, G., Fiers, M., van Ham, RCHJ., Angenent, G. C., and Immink, R. G. H. (2010). Sequence motifs in MADS transcription factors responsible for specificity and diversification of protein-protein interaction. PLOS Comput. Biol. 6:e1001017. doi:10.1371/journal.pcbi.1001017

Vekemans, D., Proost, S., Vanneste, K., Coenen, H., Viaene, T., Ruelens, P., et al. (2012). Gamma paleohexaploidy in the stem lineage of core eudicots: significance for MADS-box gene and species diversification. Mol. Biol. Evol. 29, 3793-3806. doi: 10.1093/molbev/ mss 183

Vrebalov, J., Ruezinsky, D., Padmanabhan, V., White, R., Medrano, D., Drake, R., et al. (2002). A MADS-box gene necessary for fruit ripening at the tomato ripening-inhibitor (rin) locus. Science 296, 343-346. doi: 10.1126/ science. 1068181

Wagner, G. P., and Zhang, J. (2011) The pleiotropic structure of the genotype-phenotype map: the evolvability of complex organisms. Nat. Rev. Genet. 12, 204-213. doi: 10.1038/nrg2949

Wang, W., Lu, A.-M., Ren, Y., Endress, M. E., and Chen, Z.-D. (2009). Phylogeny and classification of Ranunculales: evidence from four molecular loci and morphological data. Perspect. Plant Ecol. Evol. Syst. 11, 81-110. doi: 10.1016/j.ppees. 2009.01.001

Wilkins, R., and Lis, J. (1999). DNA distortion and multimerization: novel functions of the glutamine-rich domain of gaga factor. J. Mol. Biol. 285, 515-525. doi: 10.1006/jmbi. 1998.2356

Xiao, H., and Jeang, K. (1998). Glutamine-rich domains activate transcription in yeast saccharomyces cerevisiae. J. Biol. Chem. 273, 22873-22876. doi: 10.1074/jbc. 273.36.22873

Yalovsky, S., Rodríguez-Concepción, M., Bracha, K., Toledo-Ortiz, G., and Gruissem, W. (2000) Prenylation of the floral transcription factor APETALA1 modulates its function. Plant Cell 12, 1257-1266. doi: $10.2307 / 3871127$

Yang, Y. Z., Fanning, L., and Jack, T. (2003). The $\mathrm{K}$ domain mediates heterodimerization of the Arabidopsis floral organ identity porteins, APETALA3 and
PISTILLATA. Plant J. 33, 47-59. doi: 10.1046/j.0960-7412.2003.01473.x

Yang, Z. (2007). PAML 4: phylogenetic analysis by maximum likelihood. Mol. Biol. Evol. 24, 1586-1591. doi: $10.1093 / \mathrm{molbev} / \mathrm{msm} 088$

Conflict of Interest Statement: The authors declare that the research was conducted in the absence of any commercial or financial relationships that could be construed as a potential conflict of interest.

Received: 25 June 2013; paper pending published: 20 July 2013; accepted: 23 August 2013; published online: 17 September 2013.

Citation: Pabon-Mora N, Hidalgo $O$, Gleissberg S and Litt A (2013) Assessing duplication and loss of APETALA1/FRUITFULL homologs in Ranunculales. Front. Plant Sci. 4:358. doi: 10.3389/fpls.2013.00358

This article was submitted to Plant Evolution and Development, a section of the journal Frontiers in Plant Science. Copyright (c) 2013 Pabon-Mora, Hidalgo, Gleissberg and Litt. This is an open-access article distributed under the terms of the Creative Commons Attribution License (CC BY). The use, distribution or reproduction in other forums is permitted, provided the original author(s) or licensor are credited and that the original publication in this journal is cited, in accordance with accepted academic practice. No use, distribution or reproduction is permitted which does not comply with these terms. 